\title{
Johann Heinrich Pestalozzi: redes sociais através do princípio de wiki
}

\author{
Johann Heinrich Pestalozzi: social networking through the wiki principle
}

Simone de Lima Venancio', Magno Fonseca Borges².

\begin{abstract}
Resumo
Partindo dos verbetes disponíveis no Wikipédia, e fazendo uso do princípio wiki, buscamos compreender o ambiente social em que viveu Johann Heinrich Pestalozzi e as redes de relações por ele vivenciadas e experimentadas ao longo das primeiras etapas de sua vida.

Palavras-Chave: Johann Heinrich Pestalozzi. Redes sociais. Princípio wiki.
\end{abstract}

Como citar esse artigo. Venancio

SL, Borges MF. Johann Heinrich Pestalozzi: redes sociais através do princípio de wiki. Revista Mosaico. 2014 Jul./Dez.; $05 \quad$ (2): 25-31.

\begin{abstract}
Based on the available entries in Wikipedia, and using wiki principle, we seek to understand the social environment in which he lived Johann Heinrich Pestalozzi and the networks of relationships for he lived and experienced throughout the first stages of his life.

Keywords: Johann Heinrich Pestalozzi. Social networking. Wiki principle.
\end{abstract}

\section{Introdução}

Este pequeno texto apresenta algumas reflexões preliminares sobre as redes de relações sociais vivenciadas por Johann Heinrich Pestalozzi. As Associações Pestalozzi (cujo nome lhe é uma homenagem) estão presentes em vários municípios do Brasil. Contudo, apesar da importância social do trabalho desenvolvido por estas instituições - que promovem acesso à educação e melhoria da qualidade de vida de pessoas que possuem necessidades especiais -, até o momento inicial deste trabalho, não havíamos estudado nada sobre este pensador. Não são muito difundidas, nem na educação básica nem na superior, informações sobre Johann Heinrich Pestalozzi. É muito curioso que exista uma Associação de tamanha envergadura com o nome deste pensador e, ao mesmo tempo, que seja tão exíguo o acesso a informações sobre sua trajetória de vida.

Assim, apesar de compreendermos que existe a necessidade de estudos mais aprofundados sobre a trajetória da Associação Pestalozzi no Brasil, algumas indagações acabaram por povoar nossa mente: Afinal, quem havia sido Pestalozzi? Em qual momento e sob quais determinações sociais ele viveu? Estas são as perguntas que buscaremos responder ao longo de nosso trabalho.

Nestas primeiras notas sobre nossa pesquisa, pretendemos tratar apenas de alguns aspectos da vida de Pestalozzi - de seu nascimento até a juventude. Tentaremos construir nossa argumentação a partir da Wikipédia. Não é o objeto mais imediato deste texto compreender o papel de Pestalozzi como educador. Este ponto de nossa pesquisa ainda está em fase de elaboração. Para estes primeiros escritos, trataremos brevemente da situação social de Zurique, quando do nascimento de Pestalozzi e algumas de suas redes de relações sociais tecidas em sua juventude, durante seus estudos no Collegium Carolinum.

\section{Compartilhar + Colaborar $=$ CONHECIMENTO}

Já virou lugar comum a afirmativa de que uma das maiores características do tempo histórico atual é o acesso à informação. A chamada sociedade do conhecimento não é o objeto principal deste nosso estudo. Contudo, recorrer a esta categorização nos ajuda a situar o próprio objeto de nossa pesquisa. Conhecer melhor Johann Heinrich Pestalozzi em seu tempo histórico, seu lugar de vivência e suas redes de relações sociais é parte deste objeto. Contudo, o objeto de uma

1. Graduanda em História pela Universidade Severino Sombra.

2. Doutorando do Programa de Pós-Graduação em História da Universidade Federal do Estado do Rio de Janeiro (PPGH/UNIRIO). Professor nos cursos de Licenciatura em História e Pedagogia da Universidade Severino Sombra; 
pesquisa não se define apenas por suas questões. Integra o objeto a forma como se pretende fazer a investigação. Dito de outro modo, o método é parte integrante do objeto de pesquisa.

Foram várias as formas de produção e difusão de informações e conhecimentos ao longo da história. Também são variadas as formas como estas foram encaradas, vivenciadas e experimentadas. A mesma diversidade pode ser percebida em torno da ética que as regem. Nosso empenho em estudos está organizado a partir da ética colaborativa. O compartilhamento de ideias é muito salutar. Permite a expansão das perspectivas e ampliação das possibilidades de construção de conhecimentos. Compartilhar e colaborar são palavras com significados diferentes. Em alguma medida, compartilhar está relacionado ao ato da difusão, enquanto o colaborar reside no ato de fazer junto. Sob nosso ponto de vista, colaborar e compartilhar são percepções complementares. E é exatamente por isso que lançamos mão de uma importante iniciativa para realizar nossa investigação. Trata-se da enciclopédia universal construída de modo colaborativo: Wikipédia, a enciclopédia livre.

Os princípios éticos que regem a noção de compartilhamento e colaboração colocam em cheque as lógicas individualistas, quando pesquisadores eram estimulados a se deitarem sob seus objetos, escondendoos como tesouros intocáveis. A forma complementar como as noções de compartilhamento e colaboração são tratadas no projeto do Wikipédia aponta para uma nova ética de produção e difusão do conhecimento. As possibilidades abertas por esta nova ordem ética permite a Wikipédia um enorme dinamismo, pautado em profunda interação.

Neste espaço virtual, a relação entre compartilhar e colaborar ganha vida. Ao longo de suas páginas, é possível encontrar desde informações ainda em estado inicial de desenvolvimento, até produções mais bem elaboradas e aprofundadas. É muito interessante perceber como o compartilhamento de ideias auxilia na construção de novas perspectivas. É muito estimulante perceber como, por vezes, ideias em estágio embrionário ganham novos olhares e esforços colaborativos. Com isso, recebem corpo e ficam robustecidas. Essa multiplicidade é garantidora de um contínuo desenvolvimento.

Outro ponto fundamental a ser destacado, ainda em se tratando de ética de compartilhamento (em seu sentido complementara colaboração), reside nas políticas que fundamentam e regem os princípios fundadores da iniciativa. A Wikipédia é uma enciclopédia global, livre e gratuita. Seus conteúdos são disponibilizados sob a licença Creative Commons BY-AS, ${ }^{2}$ e podem ser copiados e reutilizados sob a mesma licença. A licença Creative Commons é a forma sob a qual se organiza a

\footnotetext{
Página inicial do Wikipédia, a Enciclopédia livre: https://pt.wikipedia.org/wiki/

Wikip\%C3\%A9dia:P\%C3\%Algina princip
}

2 http://creativecommons.org/licenses/by-sa/3.0/deed.pt
Revista Mosaico. Foi exatamente este posicionamento ético frente ao conhecimento que nos estimulou o envio destas primeiras e iniciais reflexões à Revista.

A Wikipédia (e outras iniciativas do mesmo gênero) ao repousar seus esforços sob o princípio wiki, ${ }^{3}$ tem contribuído para abalar os preceitos que fundamentaram a filosofia do conhecimento ocidental. Se o método científico ocidental (desde Descartes) propunha a extremada fragmentação do objeto, o princípio wiki pode representar a possibilidade de inversão desta ordem, a partir das múltiplas ligações entre as partes e sua religação com o todo. Uma nova kosmós está em curso e o princípio wiki é uma de suas ferramentas.

Dentre as características da Wiki estão a edição colaborativa, a utilização de hipertexto e o versionamento das modificações realizadas em algum documento. A edição colaborativa permite que qualquer usuário possa editar páginas criadas por outros usuários. A utilização de hipertexto possibilita a inserção de links nas páginas escritas para outras seções na mesma página, para outras páginas ou ainda outros endereços de Internet. Por fim, o versionamento indica o histórico de modificações de determinada página, com autores e datas de modificação. ${ }^{4}$

Partindo dos verbetes disponíveis no Wikipédia, e fazendo uso do princípio wiki, buscamos compreender o ambiente social em que viveu Johann Heinrich Pestalozzi e as redes de relações por ele vivenciadas e experimentadas ao longo das primeiras etapas de sua vida.

\section{Johann Heinrich Pestalozzi}

Johann Heinrich Pestalozzi nasceu no ano de 1746, na cidade de Zurique (que era a sede do Cantão de mesmo nome e integrava a confederação Helvética desde 1353). ${ }^{5}$ Era filho de Johann Baptist Pestalozzi e Suzanna Hotz. O pai era um cirurgião bem estabelecido na cidade de Zurique. ${ }^{6}$ A trajetória pessoal de Johann Heinrich Pestalozzi foi marcada por uma tragédia: O falecimento do pai, quando ele ainda era uma criança de apenas 5 anos. Tinha mais 3 irmãos. Desde o falecimento

\footnotetext{
3 Cf. verbete disponível no Wikipédia, a Enciclopédia livre: wiki - https://pt.wikipedia.org/wiki Wiki

4 CORREIA, Rony Rodrigues. Associações entre princípios sociotécnicos e compartilhamento de conhecimento: Estudo de caso em projetos de sistemas de informação. Perspectivas em Gestão \& Conhecimento, v. 3, n. 1, 2013. p. 181 .

A formação da Suiça tem histórico bastante singular. Foi formada, ainda em 1291 uma aliança, chamada Confederação Helvética. Esta aliança foi formada, inicialmente por comunidades que vivam no Vale dos Alpes. No momento inicial, pactuaram esta aliança os nobres das comunidades des cidades de Uri, Schwyz e Unterwalden (e sus respectivas ́́reas de influência). As bases principas cid des Uri, Sch a livre comércio entre estas unidades; o zelo e patrulhamento das estradas que cortavam e integravam estas unidades. Foi a partir de 1332 que a Confederação passou a acolher novos membros, com a entrada do Cantão de Lucena. Em 1353 o Cantão de Zurique passou a integrar a Confederação. A Confederação existiu neste formato até o ano de 1798, quando ocorreu a chamada Revolução Suíça e deu-se a formação da República Helvética (que durou apenas por 5 anos). Estas informações foram compiladas de vários verbetes disponíveis no Wikipédia, a Enciclopédia livre.

(a) História da Suíça: https://pt.wikipedia.org/wiki/Hist $\% \mathrm{C} 3 \% \mathrm{~B} 3$ ria da $\mathrm{Su} \% \mathrm{C} 3 \% \mathrm{AD} \% \mathrm{C} 3 \% \mathrm{~A} 7 \mathrm{a}$ (b) Suíça: https://pt wikipedia. org/wiki/Su\% $\%$ 33\%

(c) República Helvética: https://pt.wikipedia.org/wiki/Rep\%C3\%BAblica Helv\%C3\%A9tica; (d) Zurique: https://pt.wikipedia.org/wiki/Zurique. 6 Cf. verbete disponivel no Wikipedia: a Enciclope
de.wikipedia.org/wiki/Johann Heinrich Pestalozzi.
} 
de Johann Baptist, Suzanna Hotz passou a contar com o apoio do sogro, Andreas Pestalozzi, para a educação e sustento dos filhos.

Mesmo com o apoio de Andreas Pestalozzi, que era pastor, a família passou por grandes dificuldades financeiras. Certamente, tais dificuldades não eram semelhantes às vivenciadas pela maioria das pessoas da Suíça daquele tempo. Ainda assim, Johann Heinrich Pestalozzi experimentou o empobrecimento da família e sentiu, assim como sua mãe e seus irmãos, o preconceito do grupo em que estavam inseridos. Segundo o professor João Francisco Lopes de Lima, em Zurique, o acesso à educação era privilégio de um pequeno grupo. Mesmo empobrecido, Johann Heinrich Pestalozzi, teve acesso a estudos e a oportunidade de frequentar a Universidade de Zurique. ${ }^{7}$

Pestalozzi fez o ensino primário e o ensino secundário em Zurique, entre 1751 e 1763. Entre 1763 e 1765, estudou Linguística e Filosofia, também em Zurique, não tendo realizado por completo qualquer formação universitária. ${ }^{8}$

Como visto anteriormente, Andreas Pestalozzi era pastor protestante. ${ }^{9}$ A reforma protestante foi introduzida na Confederação Helvética por volta de 1520. Mas não foi vivida da mesma forma em todos os Cantões que integravam a confederação. Sete Cantões declararam apoio e fidelidade ao catolicismo. O Cantão de Zurique aderiu às reformas introduzidas por Ulrich Zwingli. A cisma entre cantões católicos e protestantes teve impactos na política interna dos Confederados. ${ }^{10}$

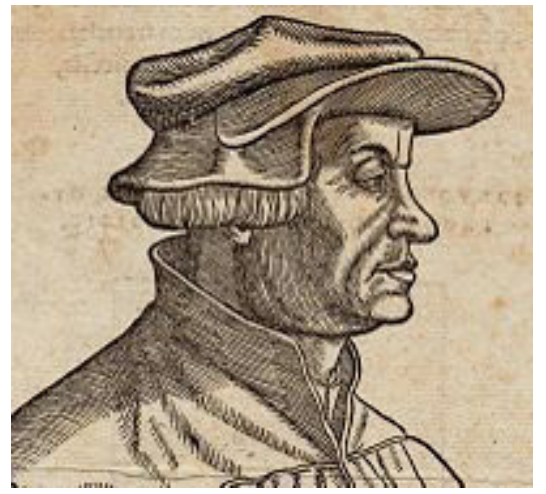

Figura 1. Ulrich Zwingli

Fonte: https://pt.wikipedia.org/wiki/ Reforma Su\%C3\%AD\%C3\%A7a

Além da tragédia pessoal, Johann Heinrich Pestalozzi viveu em um momento bastante conturbado. A tensão religiosa naquele momento estava sendo retomada e era crescente. Vários pastores começaram a tecer duras críticas à forma como se organizava a sociedade em Zurique. O aumento da pobreza era um dos temas recorrentes. A pobreza era tratada como

7 LIMA, João Francisco Lopes. Pestalozzi: o Romantismo e o nascimento da Pedagogia Social. Ciências \& Letras, n. 47, p. 124

8 Idem

9 Cf. verbete disponível no Wikipédia, a Enciclopédia livre. Johann Heinrich Pestalozzi: https:// de.wikipedia.org/wiki/Johann Heinrich Pestalozzi.

10 Cf. verbete disponivel no Wikipédia, a Enciclopédia livre. Reforma Suíça: https://pt.wikipedia. 10 Cf. verbete disponível no Wikipédia, a Encic
org/wiki/Reforma_Su\%C3\%AD\%C3\%A7a. um problema de ordem social, que era agravada pela corrupção das casas mais ricas. ${ }^{11}$

Na escola primária e nos primeiros anos de seus estudos de Linguística e Filosofia (1751-1765), Johann Heinrich Pestalozzi cursou teologia com Johann Jakob Bodmer, ${ }^{12}$ de quem recebeu muita influência. Realizou estes estudos no Collegium Carolinum,$^{13} \mathrm{em}$ Zurique, onde, embora mais novo, foi contemporâneo de Johann Heinrich Füssli, outro pensador fortemente influenciado por Bodmer.

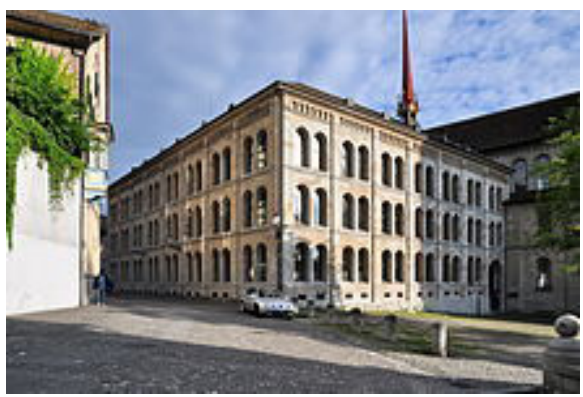

Figura 2. Collegium Carolinum

Fonte: https://de.wikipedia.org/wiki/

Collegium_Carolinum_(Z\%C3\%BCrich)

O Collegium Carolinum foi fundado em 1525 sendo o percursor da Universidade de Zurique. Foi um dos resultados da Reforma Protestante introduzidas por Ulrich Zwingli. Era a escola por onde os aspirantes a pastor deveriam passar. Seu currículo incluía estudo de Grego, Latim e Hebraico. Como parte de seu programa, também estavam incluídos os debates sobre a assistência aos pobres. Johann Jakob Bodmer foi um dos principais professores do Collegium Carolinum, ao tempo de Pestalozzi. Lecionava História e Política Helvética.

Johann Heinrich Füssli tornou-se pastor após concluir os seus estudos na Universidade de Zurique. Durante seus sermões Füssli abordava temas sociais e questionava a realidade a que a maioria da população estava exposta. A condenação pública que fazia a pobreza e a miséria, somado as contundentes críticas à política local, o levaram a ser expulso de Zurique em 1863. Além de pastor, era também pintor. Após sua expulsão, mudou-se para a Alemanha, onde estudou estética com Sulzer. Em 1864 mudou-se para a Inglaterra e em 1869 para a Italia. Em Roma, dedicouse a estudar e reproduzir obras da Antiguidade Clássica e do Renascimento. Foi um pintor importante e em suas obras podem-se perceber traços do Neoclassicismo ${ }^{14} \mathrm{e}$ do Romantismo. ${ }^{15}$ 


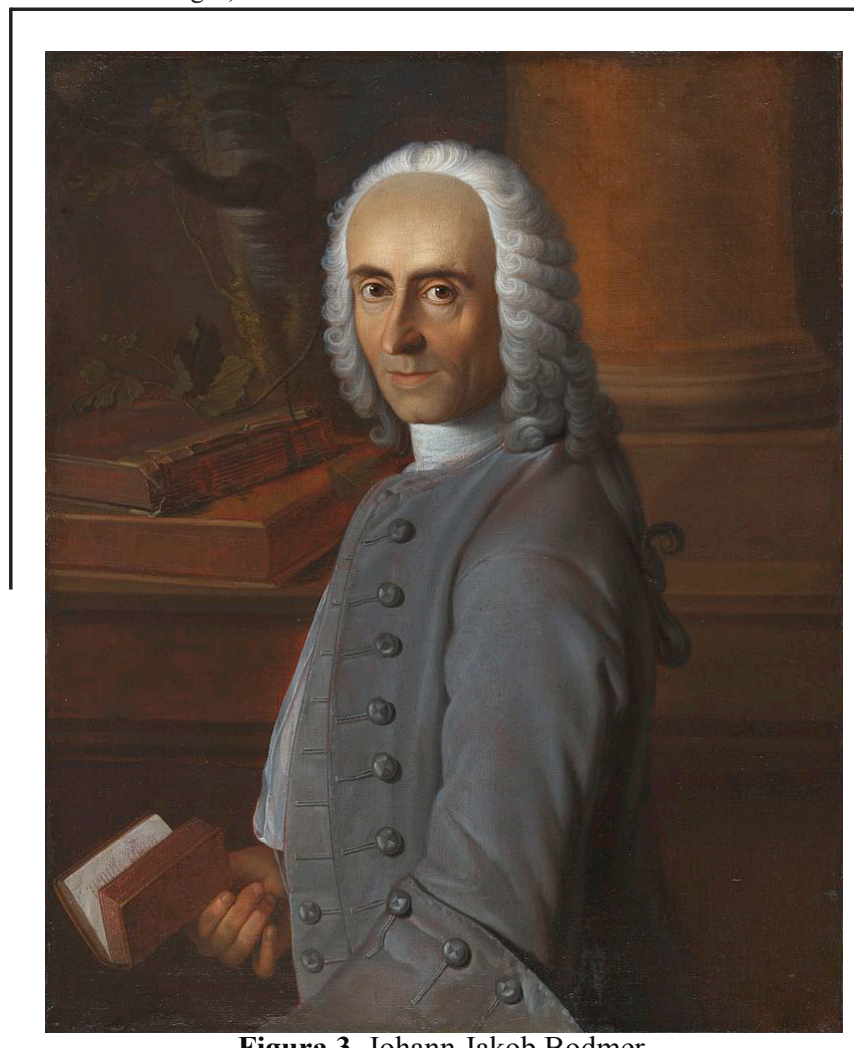

Figura 3. Johann Jakob Bodmer

Fonte: https://de.wikipedia.org/wiki/Johann_Jakob_Bodmer

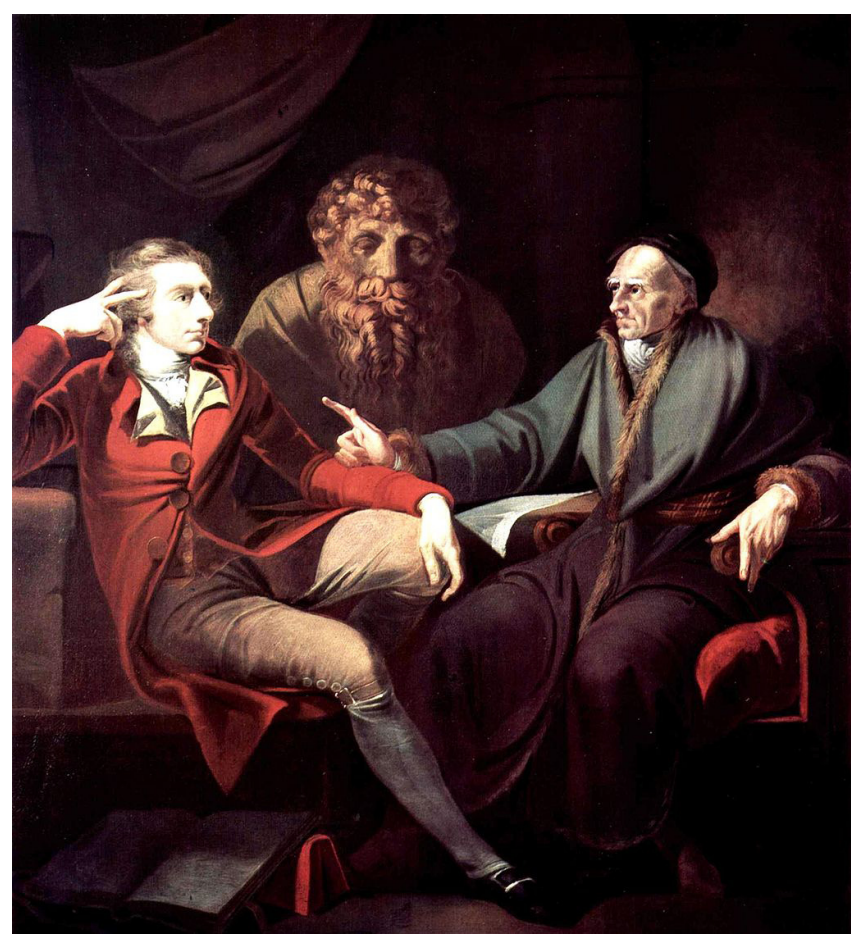

Figura 4. Johann Jakob Bodmer conversando com Johann Heinrich Füssli

Fonte: https://de.wikipedia.org/wiki/Johann_Jakob_Bodmer

Quando começou a cursar Linguística e Filosofia na Universidade de Zurique, Pestalozzi manteve grande aproximação e interlocução com seu professor Johann Jakob Bodmer. Muito por conta desta aproximação com Bodmer, Pestalozzi conviveu com Johann Heinrich Füssli. Foi também neste instante, que conheceu Johann Kaspar Lavatel, de quem foi colega de estudos. Pela convivência, pela crítica a pobreza, e em torno dos ensinamentos de Bodmer, Lavatel e Pestalozzi tornaramse amigos próximos.

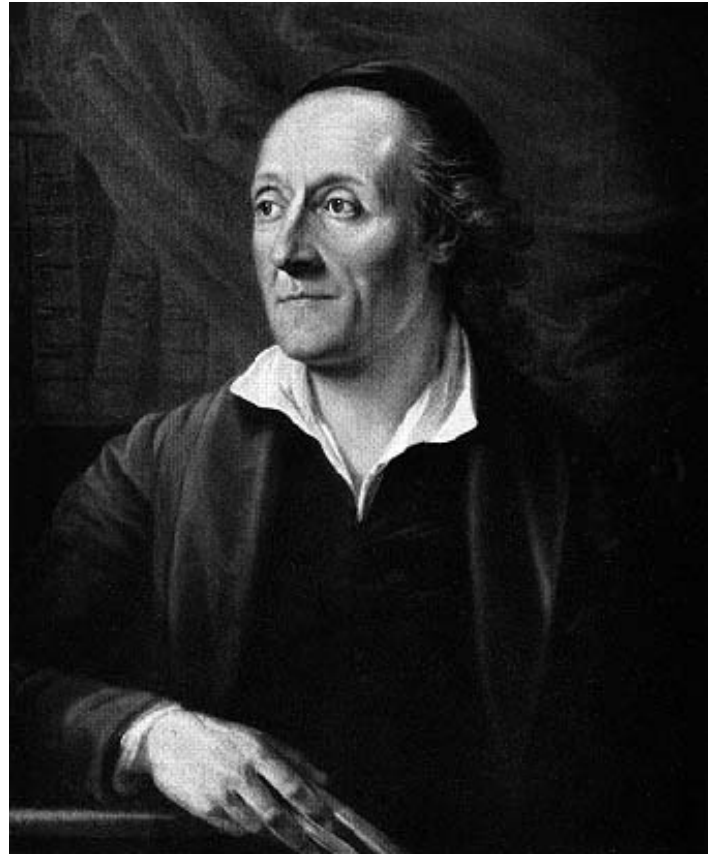

Figura 5. Johann Kaspar Lavatel

Fonte: https://pt.wikipedia.org/wiki/Johann_Kaspar_ Lavater

Johann Kaspar Lavatel foi pastor, filósofo, poeta e teólogo. ${ }^{16}$ Lavatel nasceu em 1741, também em Zurique. Junto com o amigo Johann Heinrich Füssli, Lavatel levantou-se contra a injustiça social e contra a corrupção. Em 1862 os dois iniciaram uma série de denuncias contra um Juiz de Zurique, acusando-o de enriquecimento ilícito. O Juiz foi condenado a restituir os ganhos obscuros.

O momento social era conturbado. Como vimos, por suas críticas, pela dureza de seus sermões, pela atividade política, Johann Heinrich Füssli foi expulso de Zurique, em 1863. Na França, as questões sociais, paulatinamente, ganhavam cada vez maior difusão. Ao passo que as críticas sociais ganhavam espaço em toda a Europa, em Zurique, mesmo com a expulsão de Füssli, Lavatel e Pestalozzi constituíram uma organização política para questionar a realidade local. Nesta associação, valores religiosos eram postos lado a lado com valores éticos e morais. Lavatel e Pestalozzi definiam que esta organização não era protestante, mas cristã. Com isso, visavam permitir que seus debates pudessem alcançar os diferentes espaços da Confederação Helvética.

O liberalismo compunha a agenda destes debates. Lavatel levantava-se contra o racionalismo de forma cada vez mais intensa. Pestalozzi o seguia, em parte, neste sentido. Por conta de sua atuação política, Pestalozzi não chegou a concluir seu curso. Iniciou seus estudos em Linguística e Filosofia em 1763 (mesmo ano

16 Cf verbete disponível no Wikipédia, a Enciclopédia livre. Johann Kaspar Lavatel: https:/ pt.wikipedia.org/wiki/Johann_Kaspar_Lavater. 
em que Füssli foi expulso de Zurique). Mas, em 1765, abandonou os estudos para se dedicar mais ativamente a mobilização política.

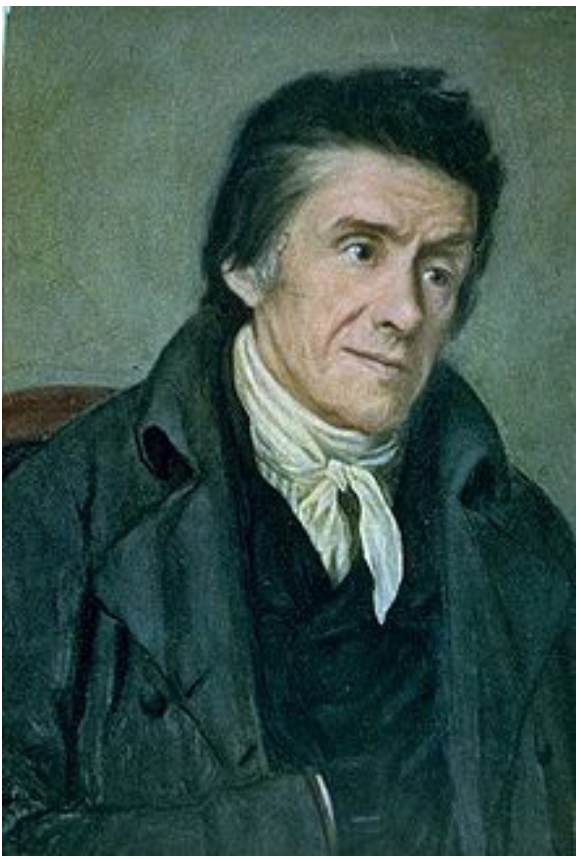

Figura 6. Johann Heinrich Pestalozzi

Fonte: https://pt.wikipedia.org/wiki/Johann_ Heinrich_Pestalozzi

É importante destacar que Pestalozzi passou por grandes dificuldades na infância, juntamente com a mãe e três irmãos, fato este que ajudou a consolidar sua personalidade predominantemente humanista, tornando-o um homem sensível e sonhador, sempre preocupado com o destino dos necessitados. Ainda estudante, já demonstrava interesse pela causa dos desamparados, participando de movimentos de reforma política e social.

\section{Conclusões preliminares}

Os diversos verbetes localizados na Wikipédia permitiram a reconstrução de uma teia de relações, que interferiram na formação da personalidade de Johann Heinrich Pestalozzi. Este nosso estudo terá continuidade. Pretendemos compreender o pensador Pestalozzi, suas formulações sobre educação e sua atuação no campo educacional. Para isso, a rede de relações sociais que pudemos perscrutar, a partir do princípio wiki, nos permitiu descobrir um jovem preocupado com as questões políticas de seu tempo.

Sendo, portanto, filho de seu tempo, inclusive quando enfrenta os excessos racionalistas e a concepção individualista de educação, pois o faz com os recursos da própria modernidade. A pretensão de ver a educação como elo transformador da humanidade a partir do melhoramento individual apenas se amplia ao pensar que esse processo deve ser estendido a todos e o coloca num tronco filosófico plenamente moderno. ${ }^{17}$
Para João Francisco Lopes de Lima, foi fundamental Pestalozzi ter tido contato com as ideias do Iluminismo de seu tempo.

Reconhecer no Iluminismo os princípios e fundamentos da obra de Pestalozzi é fundamental, pois é a partir destes que se discute a questão da infância na perspectiva do filósofo. Fazse necessário tratar desta, tendo em vista que a concepção de infância como um período distinto da vida adulta tem raízes no período aqui terminado entre os séculos XVII e XVIII. ${ }^{18}$

Verificamos que Lavatel levantou-se contra o racionalismo de seu tempo, aderindo ao empirismo. A relação de amizade entre Lavatel e Pestalozzi ultrapassou os limites do Collegium Carolinum e perdurou até o falecimento de Lavatel, em 1781. Neste momento, Pestalozzi já havia experimentado, por longo período, o engajamento nas lutas políticas. Isso the permitiu refletir sobre diversos temas, e entre estes, a Educação. Lavatel foi um dos mais presentes e influentes amigos de Pestalozzi.

Seguindo Lavatel, Pestalozzi levantou-se contra os exageros racionalistas. Para ele, vivenciar experiências podia interferir na formação do indivíduo. Por isso, defendia uma linha humanista em sua proposta educacional. Compreender um pouco melhor as teias sociais e políticas formadas por Pestalozzi nos ajuda a compreender como ele passou a compor o sem método de ensino, que se baseava em três elementos: o coração, a cabeça e a mão.

Para Pestalozzi, a cabeça representa o poder que tem o homem, graças à reflexão, de separar-se do mundo e suas impressões confusas, e de elaborar conceitos e ideias. Mas como indivíduo situado, o homem continua estando completamente submerso em um mundo que, através da experiência, não para de requerer sua sensibilidade e o vincula com seus semelhantes na luta empreendida para dominar a natureza por meio do trabalho: essa é a dimensão do coração. O homem, provocado deste modo pelo que é o requerido pelo que deve ser não tem outra solução nesse conflito sempre aberto e plenamente assumido, que fazer de si mesmo uma obra: essa é a dimensão da mão. ${ }^{19}$

Esses três pontos, em alguma medida, podem ter sido construídos a partir da forma como ele interpretava sua própria vivência. A cabeça guarda relação direta com as experiências que vivenciou no Collegium Carolinum, sob a forte influência de seu mestre Johann Jakob Bodmer. A reflexão também integrava sua relação de amizade com Lavatel. É verdade que ambos se colocaram contra os radicalismos do racionalismo. Isso não significa que dessem pouca importância ao pensamento. Para eles, a experiência e a vivência eram

18 LARA, A. M. B.; Johann Heinrich Pestalozzi (1746 - 1827): Cartas sobre educação infantil In: VIII Seminário Nacional de Estudos e Pesquisas "História, Sociedade e Educação no Brasil" HISTEDBR, 2009, Campinas - SP. Seminário Nacional de Estudos e Pesquisas História, Sociedade e Educação no Brasil. CAMPINAS: UNICAMP, 2009. p. 2

19 SOËTARD, Michel. Johann Pestalozzi / Michel Soëtard; traducão: Martha Aparecida Santana Marcondes, Pedro Marcondes, Ciriello Mazzetto; organização: João Luis Gasparin, Martha Aparecida Santana Marcondes. - Recife: Fundação Joaquim Nabuco, Editora Massangana, 2010. p. 25 . 
parte substancial para a reflexão. Sendo assim, podemos entender que sua ponderação pedagógica tem forte base nas experiências vividas e não restritas ao ambiente escolar.

$\mathrm{Na}$ realidade, no fundo desta disputa, há um debate fundamental que continua sendo de profunda atualidade na pedagogia: o da relação entre a prática e a teoria. ${ }^{20}$

Segundo Pestalozzi, a criança deve memorizar os conceitos que the foram dados, e aplicar procedimentos que the permitam achar soluções. Podemos assim entender, que a educação intelectual é fruto das impressões sensoriais obtidas pela relação entre 0 homem e a natureza, e assim, as transformam em conceitos precisos e claros. Sendo assim, o meio essencial da educação intelectual é a intuição. ${ }^{21}$

Quando pensamos sobre o segundo ponto, o coração, podemos, em alguma medida, perceber que Pestalozzi foi fortemente influenciado por algumas das leituras que realizou ao longo de seus estudos de Linguística e Filosofia na Universidade de Zurique. Foi lá que teve acesso, pela primeira vez, às obras de Rousseau. ${ }^{22}$

o século XVIII foi o século pedagógico por excelência, pois a educação passou a ocupar o primeiro plano na sociedade e duas das maiores figuras da pedagogia e da educação da infância, responsáveis por este cenário, foram Rousseau e seu discípulo Pestalozzi. ${ }^{23}$

Claramente influenciado pelas ideias de Jean Jacques-Rousseau, Pestalozzi acreditava na educação como um desenvolvimento total do indivíduo, num conjunto moral, intelectual e físico, cuja potencialidade se encontra na criança, que deve ser estimulada, principalmente no lar em que vive: "A escola deve ser a continuação do lar. É no lar que se encontra o fundamento de toda cultura verdadeiramente humana e social". 24

Podemos verificar certa junção entre a teoria de Rousseau e a sua própria experiência de vida. Após a morte se seu pai, Pestalozzi foi criado pela mãe. Para ele, a mãe é a figura central do desenvolvimento educacional. E ele entendia que o conhecimento não é propriamente adquirido, mas sim desenvolvido, pois cada ser humano já nasce com a tendência espontânea da natureza de seu próprio desenvolvimento. Somente precisa do estímulo do educador, sempre subordinado à educação moral e espiritual.

Assim sendo, o segundo ponto, o do coração

20 Idem, p. 27

21 Idem, p. 25

22 Cf. verbete disponível no Wikipédia, a Enciclopédia livre. Rousseau: https://pt.wikipedia.org wiki/Jean-Jacques_Rousseau

23 LUZURIAGA (1987) apud. GARANHANI, Marynelma Camargo; MORO, Vera Luzia. A escolarização do corpo infantil: uma compreensão do discurso pedagógico a partir do século XVШI. Educar em Revista, v, 16, n. 16, 2000, p. 111-112

24 Cf. verbete disponivel no Wikipédia, a Enciclopédia livre. Johann Heinrich Pestalozzi: https:/ 24 Cf. verbete disponivel no Wikipedia, a Enciclopedition
de.wikipedia.org/wiki/Johann Heinrich Pestalozzi. também guarda relações com sua experiência na militância política. Cabe lembrar que junto com o amigo Lavatel, Pestalozzi montou uma organização política, de cunho cristão, onde os valores religiosos eram postos lado a lado com valores éticos e morais.

O terceiro ponto de sua proposta educacional, a mão, representava, por um lado, o empirismo que tanto defendia e, por outro, tinha forte influencia do liberalismo, preparando a criança para o mundo do trabalho.

\section{Referências}

\section{Endereços visitados na Wikipédia ou através de redirecionamento por wiki:}

Creative Commos: http://creativecommons.org/licenses/by-sa/3.0/deed.pt

Verbete Collegium Carolinum: https://de.wikipedia.org/wiki/Collegium Carolinum_(Z\%C3\%BCrich)

Verbete História da Suíça: https://pt.wikipedia.org/wiki/Hist\%C3\%B3ria da_Su $\% \mathrm{C} 3 \% \mathrm{AD} \% \mathrm{C} 3 \% \mathrm{~A} 7 \mathrm{a}$;

Verbete Johann Heinrich Pestalozzi: https://de.wikipedia.org/wiki/Johann Heinrich Pestalozzi.

Verbete Johann Jakob Bodmer: https://de.wikipedia.org/wiki/Johann_Jakob_ Bodmer

Verbete Johann Kaspar Lavatel: https://pt.wikipedia.org/wiki/Johann_ Kaspar_Lavater

Verbete Neoclassicismo: https://pt.wikipedia.org/wiki/Neoclassicismo

Verbete Reforma Suíça: https://pt.wikipedia.org/wiki/Reforma $\mathrm{Su} \% \mathrm{C} 3 \% \mathrm{AD} \% \mathrm{C} 3 \% \mathrm{~A} 7 \mathrm{a}$

Verbete República Helvética: https://pt.wikipedia.org/wiki/ Rep $\%$ C3\%BAblica_Helv\%C3\%A9tica

Verbete Romantismo: https://pt.wikipedia.org/wiki/Romantismo

Verbete Rousseau: https://pt.wikipedia.org/wiki/Jean-Jacques Rousseau

Verbete Suíça: https://pt.wikipedia.org/wiki/Su\%C3\%AD\%C3\%A7a

Verbete wiki - https://pt.wikipedia.org/wiki/Wiki

Verbete Zurique: https://pt.wikipedia.org/wiki/Zurique

Wikipédia, a Enciclopédia livre: https://pt.wikipedia.org/wiki/ Wikip\%C3\%A9dia:P\%C3\%A1gina_principal

\section{Bibliográficas}

CORREIA, Rony Rodrigues. Associações entre princípios sociotécnicos e compartilhamento de conhecimento: Estudo de caso em projetos de sistemas de informação. Perspectivas em Gestão \& Conhecimento, v. 3, n. 1, p. $175-191,2013$

GARANHANI, Marynelma Camargo; MORO, Vera Luzia. A escolarização do corpo infantil: uma compreensão do discurso pedagógico a partir do século XVIII. Educar em Revista, v. 16, n. 16, 2000.

LARA, A. M. B.; Johann Heinrich Pestalozzi (1746 - 1827): Cartas sobre educação infantil. In: VIII Seminário Nacional de Estudos e Pesquisas "História, Sociedade e Educação no Brasil" HISTEDBR, 2009, Campinas - SP. Seminário Nacional de Estudos e Pesquisas História, Sociedade e Educação no Brasil. CAMPINAS: UNICAMP, 2009. 
LIMA, João Francisco Lopes. Pestalozzi: o Romantismo e o nascimento da Pedagogia Social. Ciências \& Letras, n. 47, página 124. Disponível em http://seer3.fapa.com.br/index.php/arquivos/article/view/43

SOËTARD, Michel. Johann Pestalozzi / Michel Soëtard; tradução: Martha Aparecida Santana Marcondes, Pedro Marcondes, Ciriello Mazzetto; organização: João Luis Gasparin, Martha Aparecida Santana Marcondes. Recife: Fundação Joaquim Nabuco, Editora Massangana, 2010. 112 p. 